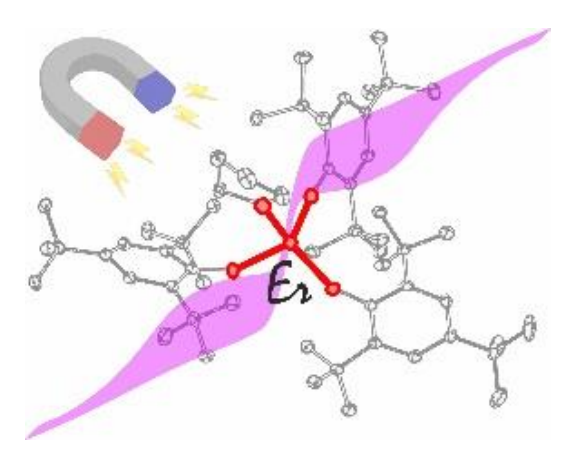

\section{Pseudo-tetrahedral vs pseudo-octahedral Er'II single molecule magnets and the 'disruptive' role of coordinated TEMPO radicals}

\author{
Maria Brzozowska, Gabriela Handzlik, Katarzyna Kurpiewska, Mikołaj Zychowicz and \\ Dawid Pinkowicz*
}

Er'll complexes are considered the most interesting candidates for high-performance single molecule magnets (SMMs) just after Dy'". Herein, we thoroughly explore the underrepresented class of neutral pseudo-tetrahedral Er'II SMMs and demonstrate their exceptional slow magnetization dynamics controlled by the Raman relaxation mechanism. We also compare their molecular magnetic memory effect in the form of a waist-restricted magnetic hysteresis loop with an example of a hexa-coordinate pseudo-octahedral Er"II SMM that does not show this effect. In this paper, we report four new neutral mononuclear Er'II complexes - three four-coordinate: [Er'"ITTBP $)_{3}$ (THF)] (1) (TTBP- = 2,4,6-tri-tert-butyl-phenolate), [Er'"'(TTBP) $)_{3}($ TEMPO)] (2) (TEMPO = 2,2,6,6-tetramethylpiperidine 1-oxyl) and $\left[\mathrm{Er}^{\prime \prime \prime}(\mathrm{BHT})_{3}(\mathrm{THF})\right]$ (3) (BHT- = 2,6-di-tert-butyl-4methylphenolate) and one hexa-coordinate: [Li(THF) $\left.)_{2}\right]_{2}\left[\mathrm{Er}^{\prime \prime \prime}\left(\mathrm{N}_{3} \mathrm{~N}\right) \mathrm{Cl}_{2}\right]$ complex (4) $\left(\mathrm{N}_{3} \mathrm{~N}=\right.$ tris(N-trimethylsilyl-2amidoethyl)amine; [( $\left.\left.\left.\mathrm{Me}_{3} \mathrm{SiNCH}_{2} \mathrm{CH}_{2}\right)_{3} \mathrm{~N}\right]^{3-}\right)$. Finally, by comparing [Er'"(TTBP) $\left.)_{3}(\mathrm{THF})\right]$ (1) and its 'TEMPO' functionalized congener [Er'"(TTBP) $)_{3}($ TEMPO)] (2), we show that adding an additional spin on the ligand of an Er'II SMM can sometimes completely disrupt their slow magnetization dynamics, instead of 'tweaking' it.

\section{Introduction}

The design of lanthanide-based single molecule magnets (Ln-SMMs) ${ }^{1}$ with the overarching goal of controlling and finetuning their magnetic properties is currently one of the hottest topics in the rapidly developing field of multifunctional molecule-based magnetic materials. ${ }^{2,3}$ This is due to the very high interest in manufacturing reliable single-molecule components for quantum information processing (QIP) applications ${ }^{4,5}$ showing quantum phase interference, ${ }^{6}$ quantum entanglement of the magnetic states, ${ }^{7}$ coherent spin manipulation ${ }^{8,9}$ and clock transitions ${ }^{10}$ as well as potential hightemperature single-molecule magnetic memory devices. ${ }^{11}$ One of the most challenging goals in this vein is the precise design and control of appropriate ligand-scafflods, ${ }^{12}$ including the number of donor atoms, their position and symmetry, and the ligand field strength, ${ }^{13}$ so that the target SMMs can perform in a completely predictable manner at the highest possible temperature. This led already to significant breakthroughs. ${ }^{11,14-}$ 17 The second, even more challenging goal, is achieving a certain degree of control over the nanomagnetism of these assemblies via external stimuli lading to the ON/OFF switching ${ }^{18-23}$ and in the long-run - the multifunctionality, so that they can perform many different functions depending on their environment and thermodynamic conditions. ${ }^{24-26}$

Usually, the lanthanide of choice for the design of highperformance SMMs is a Kramers ion Dy'III 27-35 due to its large magnetic moment and high magnetic anisotropy. However, Dy SMMs of the most appropriate geometry are mostly electrically charged ions, which prevent for example their sublimation and a straightforward deposition on neutral surfaces. ${ }^{36} \mathrm{Er}$ "ll is the most common alternative to Dy"l' with some high-performance metallocene SMM examples. ${ }^{37-43}$ Certain trigonal planar (or nearly planar) Er'll complexes of approximately $C_{3}$ symmetry with three negatively charged ligands arranged equatorially also result in well-performing and most importantly, neutral SMMs showing wide magnetic hysteresis loops of the molecular origin. ${ }^{4-47}$ Such a trigonal ligand field scaffold effectively stabilize the prolate electron density of the highly axial $m_{\mathrm{J}}=$ $15 / 2$ state. Interestingly, very good slow magnetic relaxation characteristics can still be observed even if an additional donor atom/ligand is located in the unfavourable axial position leading to pseudo-tetrahedral geometry as it was demonstrated for $\left[\mathrm{Er}{ }^{\prime \prime \prime}\left[\mathrm{N}\left(\mathrm{SiMe}_{3}\right)_{2}\right]_{3} \mathrm{Cl}\right]^{-}$anion ${ }^{45}$ and $\left[\mathrm{Er}{ }^{\prime \prime \prime}\left[\mathrm{N}\left(\mathrm{SiMe}_{3}\right)_{2}\right]_{3} \mathrm{ClLi}(\mathrm{THF})_{3}\right]_{{ }^{47}}$ This opens up important possibilities for functionalization of this family of $C_{3}$-type Er'll SMMs towards switchable nanomagnets as the fourth ligand can bear and introduce additional functions into such an SMM. Herein, we fully explore this possibility by reporting a detailed magneto-structural study of three new pseudo-tetrahedral [Er"II(TTBP) $\left.{ }_{3}(\mathrm{THF})\right](\mathbf{1})\left(\mathrm{TTBP}^{-}=2,4,6\right.$-tri-tertbutyl-phenolate), $\left[\mathrm{Er}^{\prime \prime \prime}(\mathrm{TTBP})_{3}(\mathrm{TEMPO})\right]$ (2) (TEMPO $=2,2,6,6-$ tetramethylpiperidine 1-oxyl) and $\left[\mathrm{Er}^{\prime \prime \prime}(\mathrm{BHT})_{3}(\mathrm{THF})\right](3)\left(\mathrm{BHT}^{-}=\right.$ 2,6-di-tert-butyl-4-methylphenolate) neutral complexes and, for comparison purposes, one new octahedral [ $\left.\mathrm{Li}(\mathrm{THF})_{2}\right]_{2}\left[\mathrm{Er}^{\prime \prime \prime}\left(\mathrm{N}_{3} \mathrm{~N}\right) \mathrm{Cl}_{2}\right]$ complex $(4)\left(\mathrm{N}_{3} \mathrm{~N}=\right.$ tris(N-trimethylsilyl2-amidoethyl)amine; [( $\left.\left.\mathrm{Me}_{3} \mathrm{SiNCH}_{2} \mathrm{CH}_{2}\right)_{3} \mathrm{~N}\right]^{3-}$ ) neutral erbium(III) complex. Compounds $\mathbf{1}$ and $\mathbf{3}$ show exquisite single molecule magnet behaviour even at zero DC field and a wide waistrestricted hysteresis loop at $1.8 \mathrm{~K}$, despite the presence of an axially coordinated tetrahydrofuran molecule. Interestingly, this SMM behavior is completely quenched when the THF in $\mathbf{1}$ is replaced by the non-innocent TEMPO radical resulting in a very similar but a non-SMM compound $\mathbf{2}$. Compared to the tetrahedral $\mathbf{1}$ and $\mathbf{3}$, the octahedral $\mathbf{4}$ performs worse as an SMM due to the much less favourable, higher-symmetry ligand scaffold as previously observed for several Er ${ }^{\text {III }}$ complexes with coordination numbers exceeding $6 .{ }^{48-55}$ 
Finally, our detailed magneto-structural and theoretical study of the pseudo-tetrahedral $\mathbf{1}$ and $\mathbf{3}$, clearly shows that in the presence of a small external magnetic field, the slow magnetic relaxation in these two SMMs is fully governed by the Raman relaxation process instead of Orbach in the whole investigated $A C$ magnetic susceptibility temperature and frequency range. This observation again calls for a better understanding of this most basic relaxation process in the lanthanide-based SMMs. ${ }^{56}$

\section{Results and discussion}

Compounds 1, 3 and 4 (Figure 1) are obtained by reacting $\mathrm{ErCl}_{3}$ with the corresponding sodium or lithium salts of the appropriate ligands (Figure 1e): phenolate type TTBP and BHT or tris(amido)amine type $\left[\mathrm{N}_{3} \mathrm{~N}\right]^{3-}$ in anhydrous THF. The reaction is followed by the removal of the initial solvent and recrystallization of the target compounds from $n$-pentane resulting in pink crystals sensitive to ambient atmosphere (both moisture and oxygen). Preparation of $\mathbf{2}$, on the other hand, proceeds through the substitution of the THF molecule in compound 1 by TEMPO radical in a $n$-pentane solution. Single crystal X-ray diffraction (SCXRD) structural analysis at $100 \mathrm{~K}$ and at room temperature (for details see the ESI and Tables S1 and S2) revealed that all three compounds are neutral mononuclear Er'II complexes with either pseudo-tetrahedral (1-3) or pseudooctahedral geometry (4). Note that the structure of the $\mathrm{Yb}^{\prime \prime \prime}$ analog ${ }^{57}$ of compound $\mathbf{1}$ has been reported previously. Moreover, the $\left[\mathrm{N}_{3} \mathrm{~N}\right]^{3-}$ ligand employed in the preparation of 4 has been designed and introduced by Schrock and Cummins et al. in order to enforce an open trigonal pyramidal coordination environment in some transition metal complexes. ${ }^{58,59}$

\section{Crystal structure of 1, 2 and 3}

Both 1 and $\mathbf{3}$ crystalize in a triclinic system (space group P-1) while 2 crystallizes in a monoclinic system (P2 $1 / n)$. Nevertheless, all three show very similar molecular geometries but different crystal packing caused by the presence of an additional tert-butyl group in TTBP as compared to BHT in $\mathbf{1}$ and $\mathbf{3}$ or substitution of THF by TEMPO in $\mathbf{1}$ and $\mathbf{2}$. Nevertheless, in all three cases the bulky character of the monodentate phenolate ligands leads to the four-coordinate coordination sphere of the central ion Er'll with an approximate pseudo tetrahedral geometry (Figure 1). Due to the different crystal packing, the asymmetric units (AUs) of $\mathbf{1}$ and $\mathbf{2}$ comprise only one molecule $\left[\mathrm{Er}^{\prime \prime \prime}(\mathrm{TTBP})_{3}(\mathrm{THF})\right]$ or $\left[\mathrm{Er} \mathrm{r}^{\prime \prime \prime}(\mathrm{TTBP})_{3}(\mathrm{TEMPO})\right]$, respectively while
Table 1. Selected bond lengths, molecular contacts and angles within the first coordination sphere of the Er'II' in 1, 2 and $\mathbf{3}$ at $100 \mathrm{~K}$.

\begin{tabular}{|c|c|c|c|c|}
\hline & 1 & 2 & 3 (Er1A) & 3 (Er1B) \\
\hline Er-O1 & $2.086(2)$ & $2.124(1)$ & $2.078(4)$ & $2.096(4)$ \\
\hline $\mathrm{Er}-\mathrm{O} 2$ & $2.065(2)$ & $2.049(1)$ & $2.078(4)$ & $2.072(4)$ \\
\hline $\mathrm{Er}-\mathrm{O} 3$ & $2.087(2)$ & $2.106(1)$ & $2.081(3)$ & $2.078(4)$ \\
\hline Er-O4L & $2.319(2)$ & $2.229(1)$ & $2.340(4)$ & $2.349(4)$ \\
\hline $\begin{array}{c}\text { shortest } \\
\text { Er..H }\end{array}$ & $2.5581(3)$ & $2.5349(4)$ & $2.6809(8)$ & $2.6073(11)$ \\
\hline O1-Er-O2 & $118.78(8)$ & $112.11(4)$ & $114.70(14)$ & $115.46(14)$ \\
\hline O1-Er-O3 & $109.29(7)$ & $126.36(4)$ & $117.96(15)$ & $117.00(15)$ \\
\hline O1-Er-O4 & $91.33(8)$ & $103.83(4)$ & $90.90(13)$ & $92.04(14)$ \\
\hline O2-Er-O3 & 117.93(7) & $108.21(4)$ & $113.78(14)$ & $115.18(15)$ \\
\hline O2-Er-O4 & $102.69(7)$ & $100.59(4)$ & 104.37(14) & $98.32(14)$ \\
\hline O3-Er-O4 & $113.39(7)$ & $101.90(4)$ & $111.81(13)$ & $114.80(13)$ \\
\hline C1-O1-Er & $148.90(17)$ & $145.87(9)$ & $166.6(3)$ & $161.0(3)$ \\
\hline $\mathrm{C}^{\mathrm{a}}-\mathrm{O} 2-\mathrm{Er}$ & $172.53(17)$ & $163.34(9)$ & $173.1(3)$ & $166.2(3)$ \\
\hline $\mathrm{C}^{\mathrm{b}}-\mathrm{O} 3-\mathrm{Er}$ & $147.42(16)$ & $147.98(9)$ & $150.5(3)$ & $147.5(3)$ \\
\hline
\end{tabular}

$\mathrm{C}^{\mathrm{a}}=\mathrm{C} 19$ for $\mathbf{1}$ and $\mathbf{2}, \mathrm{C} 16$ for $\mathbf{3} ; \mathrm{C}^{\mathrm{b}}=\mathrm{C} 37$ for $\mathbf{1}$ and $\mathbf{2}, \mathrm{C} 31$ for $\mathbf{3} ; \mathrm{L}=\mathrm{THF}$ for $\mathbf{1}$ and $\mathbf{3}$ TEMPO for 2

the AU of 3 comprises two complete [Er'I"(BHT) $)_{3}(\mathrm{THF})$ ] complexes. Interestingly, at room temperature the $\mathrm{AU}$ of $\mathbf{3}$ is reduced to only one molecule.

In all three cases 1-3, the Er'II center is coordinated by three oxygen atoms of the phenolate ligands with the average $\mathrm{Er}-\mathrm{O}$ distance of 2.079(12), 2.093(39) and 2.081(8) Å for 1, 2 and 3, respectively, and one oxygen atom of the THF (1 and $\mathbf{3}$ ) or TEMPO molecule (2) at a significantly greater distance of 2.319(2) $\AA$ (THF in 1), 2.340(4) $\AA$ (THF in 3) and 2.229(1) $\AA$ (TEMPO in 2). Interestingly, due to the low coordination number, there are also some agostic/ anagostic ${ }^{60}$ contacts between Er'II and the tert-butyl groups of the phenolate ligands with the shortest $\mathrm{Er} \cdots \mathrm{H}$ distances of 2.5581(3), 2.5349(4) and 2.6073(11) Å in 1, 2 and 3, respectively. Intramolecular contacts of this type are not uncommon in the case of unsaturated lanthanide complexes. ${ }^{61,62}$

Table 1 presents the most important bond lengths and angles within the first coordination sphere of the Er'll ions demonstrating some deviation from the ideal tetrahedral geometry which optimizes additional stabilizing electrostatic contacts with the tert-butyl groups of the TTBP and BHT ligands. Nevertheless, the results of the continuous shape measure (CShM) analysis for four-vertex polyhedral (SHAPE software) ${ }^{63}$ indicates that the first coordination sphere of Er'II in 1-3 is still best described as a distorted tetrahedron (Table S3 in the ESI).

The analysis of the TEMPO geometry in compound 2, specifically the nitroxide group with the N1-O4 distance of 1.296(2) A, indicates similarities to other Ln-TEMPO coordination compounds, ${ }^{64-66}$ and confirms that TEMPO retains its radical character in $\mathbf{2 .}{ }^{67}$ 


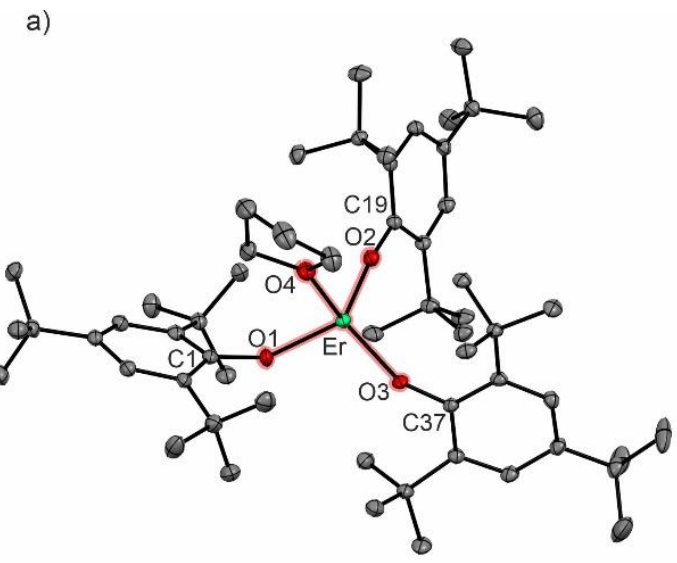

c)

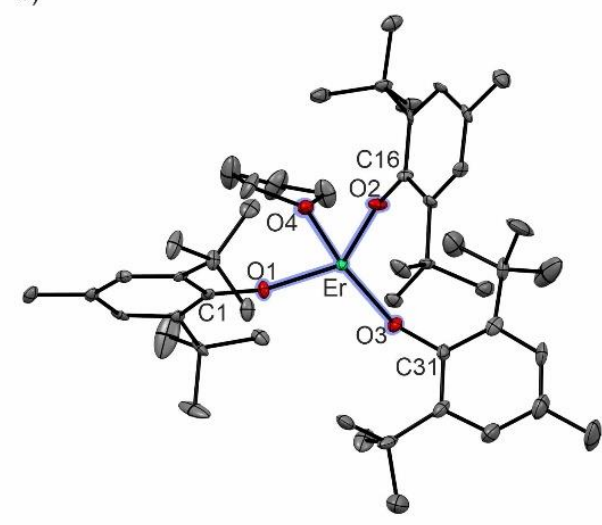

e)<smiles>CC(C)(C)c1cc([O-])c(C(C)(C)C)c(C(C)(C)C)c1</smiles>

TTBP<smiles>CC1(C)CCCC(C)(C)N1[O]</smiles>

TEMPO

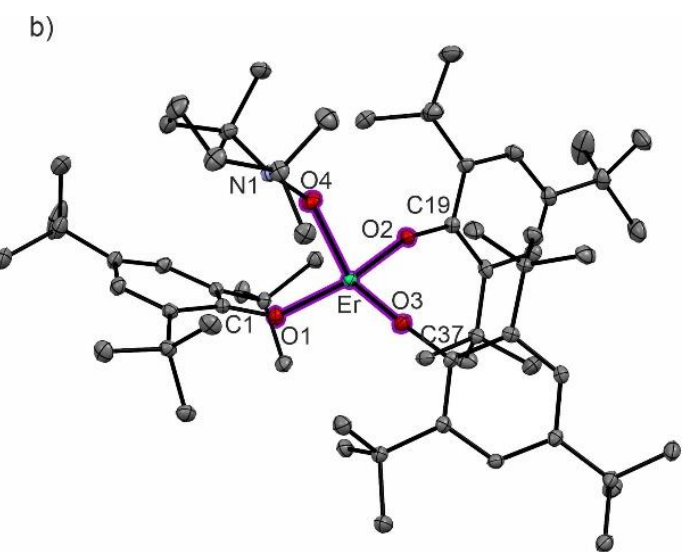

d)
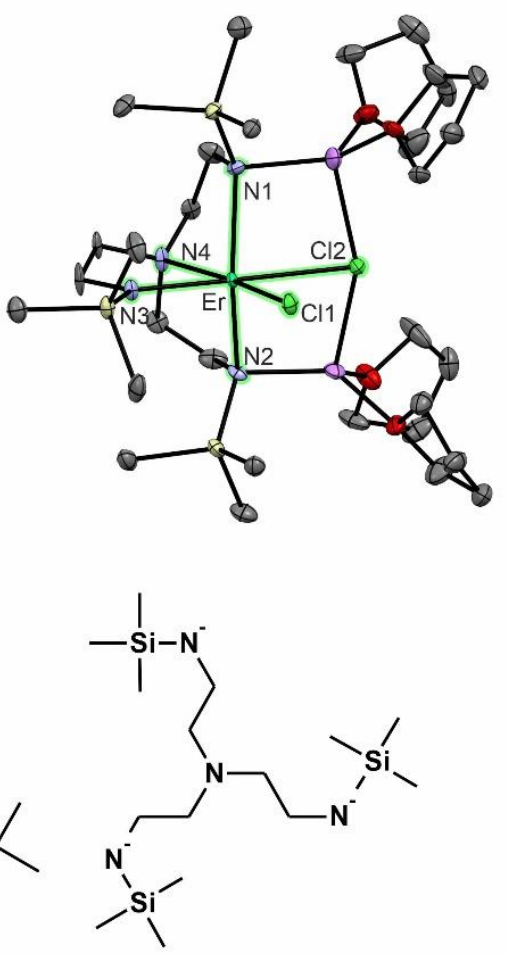

$\mathrm{N}_{3} \mathrm{~N}$

Figure 1. The crystal structure diagrams of the complexes $\mathbf{1}$ (a), $\mathbf{2}$ (b), $\mathbf{3}$ (c) and $\mathbf{4}$ (d) with selected atom labelling scheme and the structural formulae of the ligands used in this study (e): TTBP (compounds $\mathbf{1}$ and $\mathbf{2}$ ), TEMPO (compound $\mathbf{2}$ ), BHT (compound $\mathbf{3}$ ) and $\mathrm{N}_{3} \mathrm{~N}$ (compound 4). Ellipsoids are drawn at the $50 \%$ probability level and $\mathrm{H}$ atoms are omitted for the sake of clarity.

The intermolecular contacts in the series of the pseudotetrahedral 1-3 are dominated by the van der Waals

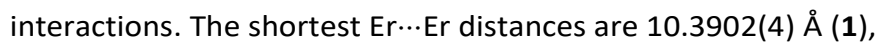

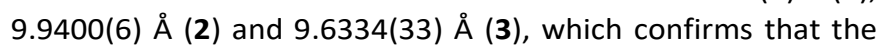
separation of the Er'll centres in the crystal lattice is better in 1 than in $\mathbf{3}$ (see Figure S2 in the ESI for the corresponding crystal packing diagrams). This is expected taking into account the bulkier character of the TTBP as compared to BHT - especially the presence of the additional tert-butyl group in TTBP. Nevertheless, in both cases $\mathbf{1}$ and $\mathbf{3}$ the magnetic interactions between the paramagnetic Er'II centres should be very weak and enable the observation of slow relaxation of the magnetization.

In the case of $\mathbf{2}$, on the other hand, the coordinated radical TEMPO is expected to strongly affect its magnetic properties compared to the parent compound $\mathbf{1}$, as the direct coordination of a $S=1 / 2$ ligand to a paramagnetic metal center always results in significant magnetic interactions. 68 


\section{Crystal structure of 4}

Compound 4 crystallizes in a monoclinic crystal system, space group $\mathrm{P} 2_{1} / \mathrm{c}$ and comprises neutral mononuclear Er ${ }^{\prime \prime \prime}$ complexes $\left[\mathrm{Li}(\mathrm{THF})_{2}\right]_{2}\left[\mathrm{Er}^{\prime \prime \prime}\left(\mathrm{N}_{3} \mathrm{~N}\right) \mathrm{Cl}_{2}\right]$ (AU) with the central ion being coordinated by four nitrogen atoms of the trianionic chelating $\left[\mathrm{N}_{3} \mathrm{~N}\right]^{3-}$ ligand and two chloride anions. The negative charge of the first coordination sphere is balanced by two [Li(THF $\left.)_{2}\right]^{+}$ cationic moieties 'attached electrostatically' to the side of the complex via $\mathrm{N}$ and $\mathrm{Cl}$ atoms (Figure $1 \mathrm{~d}$ ). The higher coordination number in 4 as compared to 1-3 is caused by the spatially restricted character of the $\left[\mathrm{N}_{3} \mathrm{~N}\right]^{3-}$ chelating ligand which cannot block all coordination sites of the large Er ${ }^{\prime \prime \prime}$ ion by itself as in transition metal complexes and enables the approach of two additional $\mathrm{Cl}^{-}$anions. Two additional $\mathrm{Li}^{+}$cations balance the 2negative charge of the first coordination sphere. Table 2 gathers the most important bond lengths and angles in 4. Noteworthy, one of the chloride ligands is located as far as 2.853(1) $\AA$ from the metal center, however, the Er'II coordination sphere can still be described as pseudo-octahedral according to the results of the CShM analysis for six-vertex polyhedral (SHAPE software) ${ }^{69}$ (Table S3 in the ESI).

Table 2. Selected bond lengths, molecular contacts and angles within the first coordination sphere of the Er"II in 4 at $100 \mathrm{~K}$.

\begin{tabular}{cccccc}
\hline length & $\AA$ & angle* & deg. & angle* & deg. \\
Er-N1 & $2.380(4)$ & N1-Er-N3 & $100.8(2)$ & N2-Er-Cl1 & $109.3(1)$ \\
Er-N2 & $2.378(4)$ & N1-Er-N4 & $72.8(2)$ & N2-Er-Cl2 & $78.6(1)$ \\
Er-N3 & $2.267(4)$ & N1-Er-Cl1 & $109.4(1)$ & N3-Er-N4 & $75.4(1)$ \\
Er-N4 & $2.446(4)$ & N1-Er-Cl2 & $78.4(1)$ & N3-Er-Cl1 & $95.6(1)$ \\
Er-Cl1 & $2.597(1)$ & N2-Er-N3 & $100.6(2)$ & Cl2-Er-Cl1 & $86.74(4)$ \\
Er-Cl2 & $2.853(1)$ & N2-Er-N4 & $73.1(2)$ & Cl2-Er-N4 & $102.3(1)$
\end{tabular}

*angle values are given with one decimal place accuracy

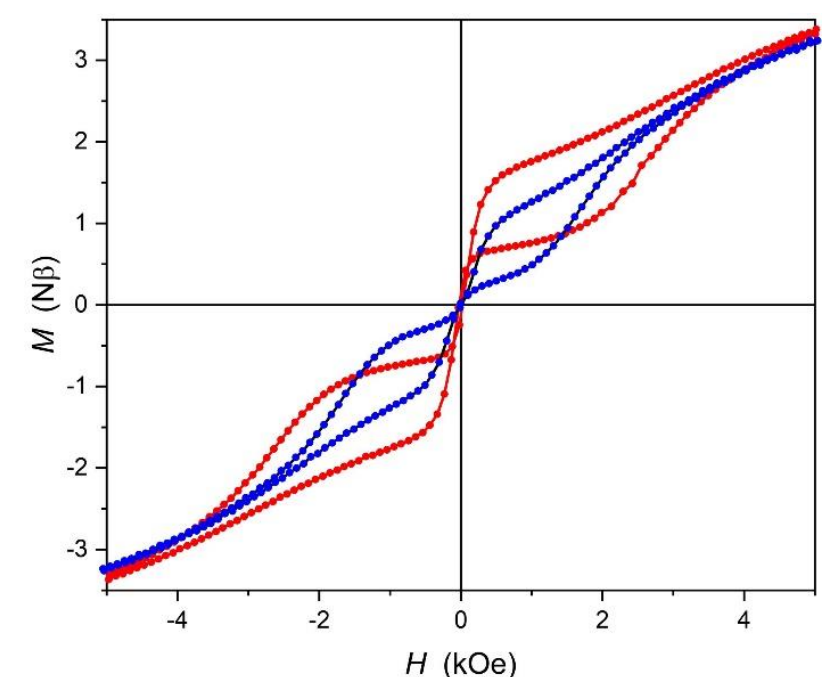

Figure 2. Magnetic hysteresis loops for compounds $\mathbf{1}$ (red) and $\mathbf{3}$ (blue) recorded at $1.8 \mathrm{~K}$ with
Similar to 1-3, the intermolecular contacts between the $\left[\mathrm{Li}(\mathrm{THF})_{2}\right]_{2}\left[\mathrm{Er}^{\prime \prime \prime}\left(\mathrm{N}_{3} \mathrm{~N}\right) \mathrm{Cl}_{2}\right]$ molecules are dominated by van der Waals interactions between the $-\mathrm{CH}_{3}$ groups of the $\mathrm{N}_{3} \mathrm{~N}$ and the $>\mathrm{CH}_{2}$ groups of THF molecules. Individual Erll' centers in $\mathbf{4}$ are separated from each other by more than $10.0172(8) \AA$ (shortest Er...Er distance) providing sufficient magnetic isolation for the observation of slow magnetic relaxation.

\section{DC magnetic properties}

The direct current (DC) magnetic properties of 1-4 were measured in the $2-300 \mathrm{~K}$ range at 100 Oe magnetic field and in the $-70.0-70.0 \mathrm{kOe}$ range at $1.8 \mathrm{~K}$. The temperature dependence of the $\chi_{\mathrm{M}} T\left(\chi_{\mathrm{M}}-\right.$ molar magnetic susceptibility) and $M(H)(M-$ molar magnetization, $H$-magnetic field strength) are presented in Figures S3-S7 in the ESI.

On cooling, compounds $\mathbf{1}, \mathbf{3}$ and $\mathbf{4}$ show a gradual decrease of $\chi_{\mathrm{M}} T$ from $11.4,11.5$ and $11.3 \mathrm{~cm}^{3} \cdot \mathrm{K} \cdot \mathrm{mol}^{-1}$ at $300 \mathrm{~K}$ and reach $9.6,9.5$ and $8.3 \mathrm{~cm}^{3} \cdot \mathrm{K} \cdot \mathrm{mol}^{-1}$ at $2 \mathrm{~K}$, respectively. These $\chi_{\mathrm{M}} T$ values are in agreement with $11.48 \mathrm{~cm}^{3} \cdot \mathrm{K} \cdot \mathrm{mol}^{-1}$ expected in the free-ion approximation $\left({ }^{4} I_{15 / 2}, g_{\lrcorner}=6 / 5\right)^{70}$ and the observed gradual $\chi_{\mathrm{M}} T(T)$ decrease is ascribed to the depopulation of the excited $m_{\mathrm{J}}$ states. The $\chi_{\mathrm{M}} T(T)$ for $\mathbf{2}$ is different, its value at $300 \mathrm{~K}$ is $11.8 \mathrm{~cm}^{3} \cdot \mathrm{K} \cdot \mathrm{mol}^{-1}\left(0.4\right.$ higher than $11.4 \mathrm{~cm}^{3} \cdot \mathrm{K} \cdot \mathrm{mol}^{-1}$ observed for its 'parent' compound 1 ) the $\chi_{\mathrm{M}} T$ decreases mildly with the lowering of the temperature down to $5 \mathrm{~K}$ but then an abrupt decrease is observed reaching $9.7 \mathrm{~cm}^{3} \cdot \mathrm{K} \cdot \mathrm{mol}^{-1}$ at $2 \mathrm{~K}$. These differences (Figure S7 in the ESI) can only be explained by the presence of the coordinated TEMPO radical $(S=1 / 2)$, which adds to the total $\chi_{\mathrm{M}} T$ value at $300 \mathrm{~K}$ and couples antiferromagnetically with Er'II causing the abrupt $\chi_{\mathrm{M}} T(T)$ decrease below $5 \mathrm{~K}$.

The $M(H)$ curves for compounds $\mathbf{1}, \mathbf{3}$ and $\mathbf{4}$ look very similar with only some subtle differences. A steep increase of the magnetization in the $0-10$ kOe range is followed by a small rise reaching 4.78, 4.72 and $5.26 \mu_{\mathrm{B}}$ at $70 \mathrm{kOe}$ for $\mathbf{1}, 3$ and 4 , respectively, without a clear plateau. Slightly higher value for $\mathbf{4}$ than in $\mathbf{1}$ and $\mathbf{3}$ is caused by slightly lower-lying excited $m_{\mathrm{J}}$ levels for this compound. The $M(H)$ curve for $\mathbf{2}$, on the other hand reaches significantly higher value at $70 \mathrm{kOe}\left(5.55 \mu_{\mathrm{B}}\right)$ than the 'parent' 1 due to the presence of an additional spin carrier - the TEMPO ligand - coordinated to the Er'II metal center. Interestingly, fast $M(H)$ measurements in the -70 to $70 \mathrm{kOe}$ window (the full hysteresis loop recorded at $200 \mathrm{Oe} \cdot \mathrm{s}^{-1}$ ) reveals waist-restricted magnetic hysteresis loops for $\mathbf{1}$ and $\mathbf{3}$ (Figure 2), while $\mathbf{2}$ and $\mathbf{4}$ show no magnetic memory effect. Noteworthy, the hysteresis loop for $\mathbf{1}$ is significantly broader than for $\mathbf{3}$ which is in agreement with the results of slow magnetization dynamics studied using AC magnetic susceptibility measurements (see below). 

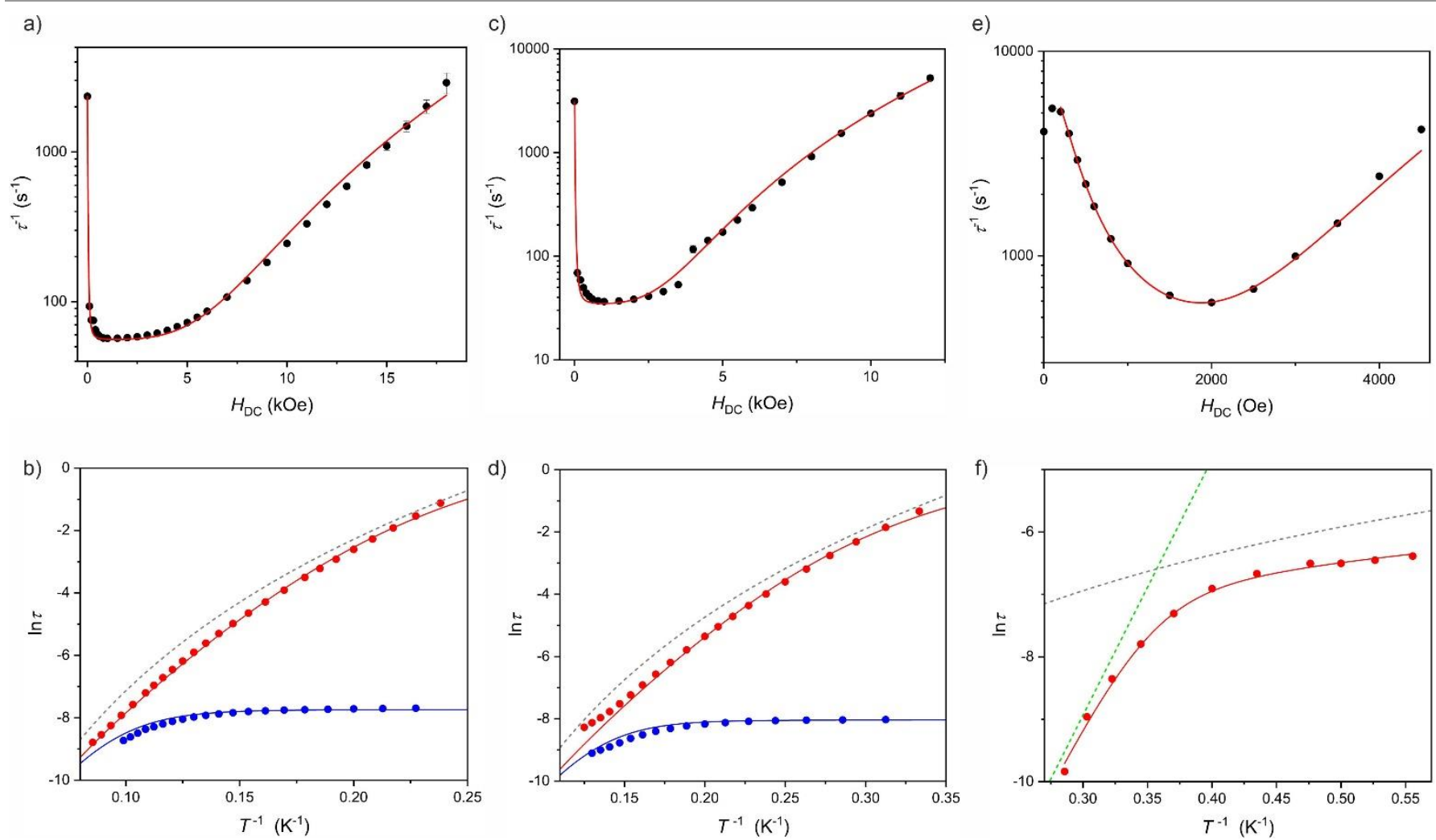

Figure 3. Magnetization relaxation times vs. magnetic field ( $a, c$ and e) and vs. temperature (b, $d$ and $f$ ) for compounds $\mathbf{1}$ (a and b), 3 (c and d) and $\mathbf{4}$ (e and $f$ ). The experimental $\tau^{1}\left(H_{\mathrm{dc}}\right)$ data points were obtained by collecting AC magnetic susceptibility data at $6.0 \mathrm{~K}(\mathrm{a}), 3.0 \mathrm{~K}(\mathrm{c})$ and $1.8 \mathrm{~K}$ e) and the experimental In $\tau\left(T^{-1}\right)$ were obtained at 0 Oe (panel b - blue points), 1000 Oe (panel b - red points), at 0 Oe (panel $d$ - blue points), 1500 Oe (panel d - red points) and 2000 Oe (panel $f$ - red points). The solid lines are the best fits using eq. 2 for ( $a, c$ and e) or eq. 3 (b, $d$ and f). Please note that in the case of (b) and (d), both dependences are fitted simultaneously for details see ESI. The dashed gray lines in (b), (d) and (f) represent the Raman relaxation process and the green dashed line in (f) represent the Orbach process.

\section{AC magnetic properties and slow magnetization dynamics}

All reported compounds were subjected to alternating-current (AC) magnetic susceptibility measurements in the $1-1000 \mathrm{~Hz}$ range at various temperatures and DC magnetic fields. Compounds $\mathbf{1}$ and $\mathbf{3}$ exhibit slow magnetic relaxation in the absence of the external DC magnetic field while 4 shows only field-induced relaxation and $\mathbf{2}$ does not show any $A C$ magnetization dynamics in the investigated frequency, temperature and magnetic field range. Both, the DC magnetic field as well as temperature dependences of the $\chi_{\mathrm{AC}}$ frequency scans were recorded and the obtained curves analysed using the generalized Debye model. ${ }^{71}$ The fitting details to the generalized Debye model as well as the $\chi_{\mathrm{AC}}(v)$ plots $(v-\mathrm{AC}$ magnetic field frequency) are presented in the ESI for each compound (sections AC1-AC4 in the ESI). Below is the detailed description of the fitting of the obtained relaxation times with a thorough analysis and the discussion of the obtained temperature and magnetic field dependences of the relaxation times of the magnetization $\tau$. In the case of Kramers ions such as Er'II, $\tau^{-1}$ can be expressed as the sum of four different relaxation mechanisms: quantum tunnelling of magnetization (QTM), direct, Raman and Orbach (Equation 1): 72,73

$$
\tau^{-1}=A_{1} /\left(1+A_{2} H^{2}\right)+B H^{4} T+C T^{n}+\tau_{0}^{-1} \exp \left(-U_{\text {eff }} / \mathrm{k}_{\mathrm{B}} T\right) \quad \text { (Eq. 1) }
$$

The isothermal magnetic field dependence of $\tau$ extracted from the magnetic field dependence of $\chi_{\mathrm{AC}}(v)$ was fitted using Equation 2:

$$
\tau^{-1}(H)=A_{1} /\left(1+A_{2} H^{2}\right)+B_{1} H^{4}+D
$$

where the first term corresponds to the quantum tunnelling of magnetization (QTM), the second stands for the direct relaxation process with $B_{1}=B T$ and the constant value $D$ describes the contribution of the field-independent processes: Raman and Orbach.

Subsequently, the isofield temperature dependences of the relaxation times $\tau$ extracted from the temperature dependence of $\chi_{\mathrm{AC}}(v)$ were fit using Equation 2 below:

$$
\ln \tau\left(T^{-1}\right)=\ln \left[\left(A+B_{2} T+C T^{\mathrm{n}}+\tau_{0}^{-1} \exp \left(-U_{\mathrm{eff}} / \mathrm{k}_{\mathrm{B}} T\right)\right)^{-1}\right]
$$

where the first term $A$ is related to the QTM relaxation and is close to zero for non-zero magnetic field, the second is the direct process with $B_{2}=B H^{4}, C$ and $n$ describe the Raman relaxation process (or phonon bottle-neck process if $n=2$ ) and the last part characterizes the contribution from the Orbach relaxation, where $\tau_{0}$ is the attempt time of relaxation, $U_{\text {eff }}$ is the effective energy barrier for magnetization reversal and $k_{\mathrm{B}}$ is the 
Boltzmann constant. Note that in the case of compounds $\mathbf{1}$ and 3 both temperature dependencies of the relaxation times recorded at 0 and the optimum DC magnetic field were fitted simultaneously with the same set of parameters describing the Raman and Orbach relaxation mechanisms (see sections AC1 and AC3 in the ESI for details and Figure 3). Both compounds show very similar $\tau^{-1}(H)$ and $\ln \tau\left(T^{-1}\right)$ dependences in accordance with quite similar coordination spheres (Table 1 and S3). The most significant difference concerns the energy barrier for the magnetization reversal: $44(2) \mathrm{cm}^{-1}(63(3) \mathrm{K})$ for compound 1 and $33(2) \mathrm{cm}^{-1}(48(3) \mathrm{K})$ for compound 3 , which is surprising, taking into account the aforementioned almost identical coordination spheres and similar results of the CASSCF calculations (see below) with the lowest lying excited KD placed more than 100 $\mathrm{cm}^{-1}$ above the ground KD for both compounds. This indicates that the effective energy barriers $U_{\text {eff }}$ for $\mathbf{1}$ and $\mathbf{3}$ are very strongly underestimated due to the operation of various Raman relaxation processes, typically encountered in molecular crystals (reasonable fits could only be obtained when $n$ was fixed at 7). ${ }^{56} \mathrm{~A}$ closer look at Figures $3 \mathrm{~b}$ and $3 \mathrm{~d}$, and the comparison of the experimental points (red circles), the best fits (red lines) and the Raman relaxation contributions (gray dashed lines), clearly demonstrates that in the whole investigated temperature range, the slow magnetization dynamics of $\mathbf{1}$ and 3 is controlled almost solely by the Raman relaxation. Compound 4, on the other hand, shows a completely different behavior which is not surprising, taking into account that it is a six-coordinate pseudo-octahedral and not pseudo-tetrahedral Er'll complex with more rigid ligand scaffold. The effective energy barrier is $28(5) \mathrm{cm}^{-1}(41(8) \mathrm{K})$ which is in good agreement with the calculated energy of the first excited state of $31 \mathrm{~cm}^{-1}$ indicating that Orbach relaxation mechanism is in operation in this case and Raman is of much less importance.

1 and $\mathbf{3}$ are both pseudo-tetrahedral complexes with one weakly bonded THF molecule and three strongly coordinated and negatively charged phenolate ligands - all located in the vertices. Despite the presence of the O-coordinated THF, the approximate axial trigonal symmetry of the coordination sphere of $\mathbf{1}$ and $\mathbf{3}$ still supports the prolate $f$-electron density of the $m_{\mathrm{J}}$ $=15 / 2$ ground state and enables the observation of a magnetic hysteresis at low temperature. Noteworthy, the 'slow magnetic relaxation' performance of $\mathbf{1}$ and $\mathbf{3}$ as compared to the THF-free trigonal-pyramidal Er'II(BHT) $)_{3}$ reported by Yamashita et al. is comparable, despite the presence of an additional Ocoordinated THF molecule along the $z$ axis of the complex. This indicates that the replacement of the THF by bridging functional ligands (e.g. photochromic, photoluminescent, chiral or electroactive) should proceed without the loss of the interesting magnetic relaxation characteristics, hence, achieving multifunctionality with these systems is a real possibility which is currently explored in our laboratory. However, the example of compound $\mathbf{2}$ which is very similar to the 'parent' $\mathbf{1}$ (as demonstrated in Table 1, Table S3 and Figure $1 \mathrm{a}$ and $1 \mathrm{~b}$ ), but has the THF replaced by a paramagnetic TEMPO $(S=1 / 2)$, indicates that not all molecules are suitable for functionalization of $\mathbf{1}$ or $\mathbf{3}$. Compound $\mathbf{2}$ shows no magnetic hysteresis nor slow magnetization dynamics within the available AC magnetic susceptibility measurement range despite being structurally very similar to $\mathbf{1}$ and $\mathbf{3}$. Since the $a b$ initio calculations for a hypothetical 'TEMPO-spin-stripped' $\mathbf{2}$ (for details see the $a b$ initio calculations section below) are still very similar to $\mathbf{1}$ and $\mathbf{3}$, the 'loss' of the SMM behavior in $\mathbf{2}$ is most probably caused by the 'disruptive' influence of the magnetic moment of TEMPO radical $(S=1 / 2)$ directly coordinated to $\mathrm{Er}^{\prime \prime l}$ in the axial position. The coordinated TEMPO must enable a very efficient magnetic relaxation pathway via the weak antiferromagnetic superexchange interaction (which reveals itself as an abrupt decrease of the $\chi T$ value at low temperatures - Figure S4 and S7 in the ESI) and 'switches off' the molecular magnetic memory observed in its parent THF-derivative 1.

Compound $\mathbf{4}$ is pseudo-octahedral and this coordination geometry is much less suited to support magnetization blocking in Er'll SMMs as it might significantly destabilize the prolate $m_{\mathrm{J}}=$ $15 / 2$ ground state and lead to better stabilization of the excited states.

\section{Ab initio calculations}

The CASSCF/CASPT2/RASSI/SINGLE_ANISO ab initio calculations were performed using the OpenMolcas software ${ }^{74}$ for the SCXRD structural models of 1, $\mathbf{3}$ and $\mathbf{4}$ (please see also the 'Ab initio calculations' section in the ESI, Tables S10-S17 for details and Figure 4). The ground state doublet for $\mathbf{1}$ and $\mathbf{3}$ is almost pure $\mid \pm 15 / 2>m_{\text {s }}$ state while the ground state for 4 contains also significant contributions from $\mid \pm 13 / 2>$ and $\mid \pm 11 / 2>$ (for further details see Tables S11-S13 in the ESI). The ground state Kramers doublets (KDs) for $\mathbf{1}, \mathbf{3}$ and $\mathbf{4}$ have a strongly axial character as presented in Tables S11-S13) and the associated easy magnetization axes for these compounds are depicted as blue arrows in Figure 4.

The first excited KD state is placed 104, 95 and $31 \mathrm{~cm}^{-1}$ above the $\mid \pm 15 / 2>$ ground state for $\mathbf{1}, \mathbf{3}$ and $\mathbf{4}$, respectively. This fact, together with the magnetization relaxation pathways, based on the magnetic transition moments between states depicted in Figure 4 (as calculated using OpenMolcas with SINGLE_ANISO module ${ }^{75}$ ), explains why $\mathbf{1}$ and $\mathbf{3}$ show much slower magnetization dynamics than $\mathbf{4}$. The relaxation for compound 4 seems to be straightforward. It proceeds mainly through the Orbach mechanism (red arrows in Figure 4c) involving the first excited state lying $31 \mathrm{~cm}^{-1}$ above the ground state, which is fully consistent with the experimental effective energy barrier for magnetization reversal of $28(5) \mathrm{cm}^{-1}$ and the conclusions drawn by others regarding the Er"ll SMMs. ${ }^{76}$ The Orbach relaxation is followed by an efficient Raman relaxation (Figure 4c) and the temperature assisted quantum tunnelling of magnetization (TAQTM; blue arrows in Figure 4c) from the first excited state, leading to a complete reversal of the magnetization. 
a)
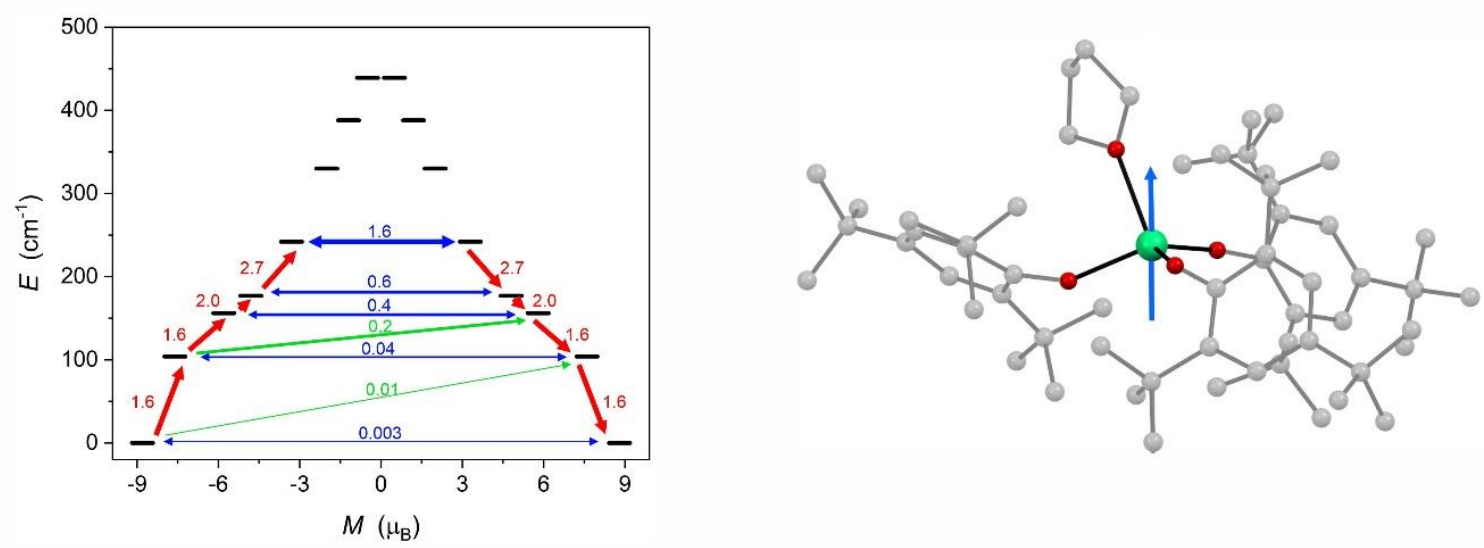

b)
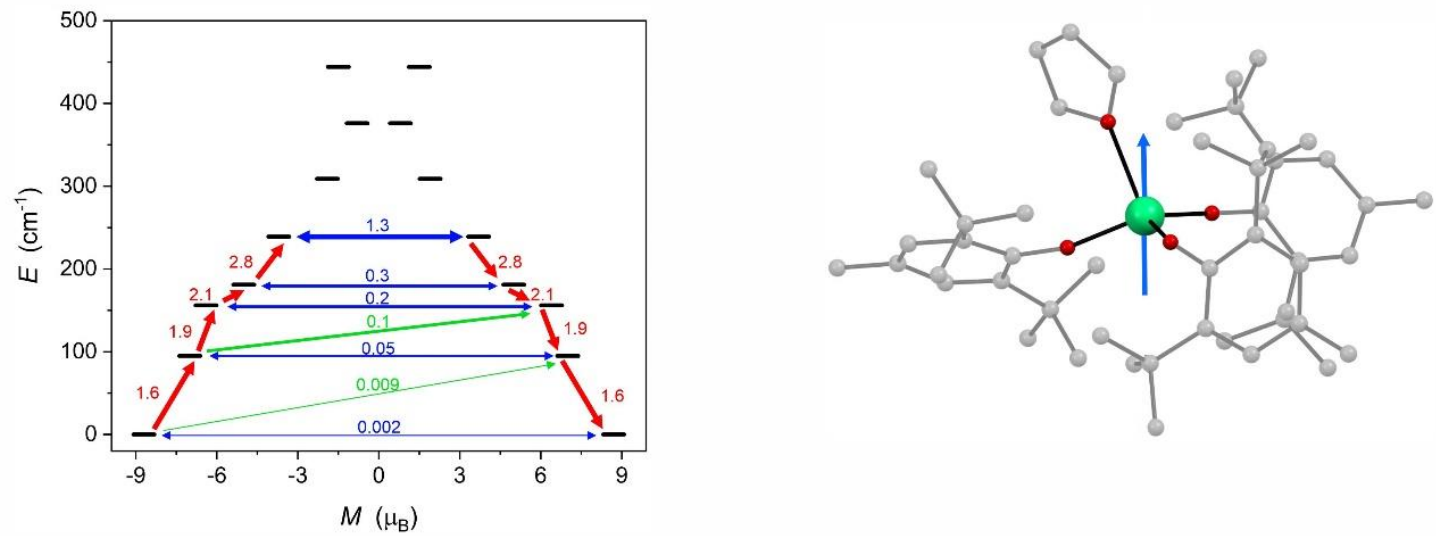

c)
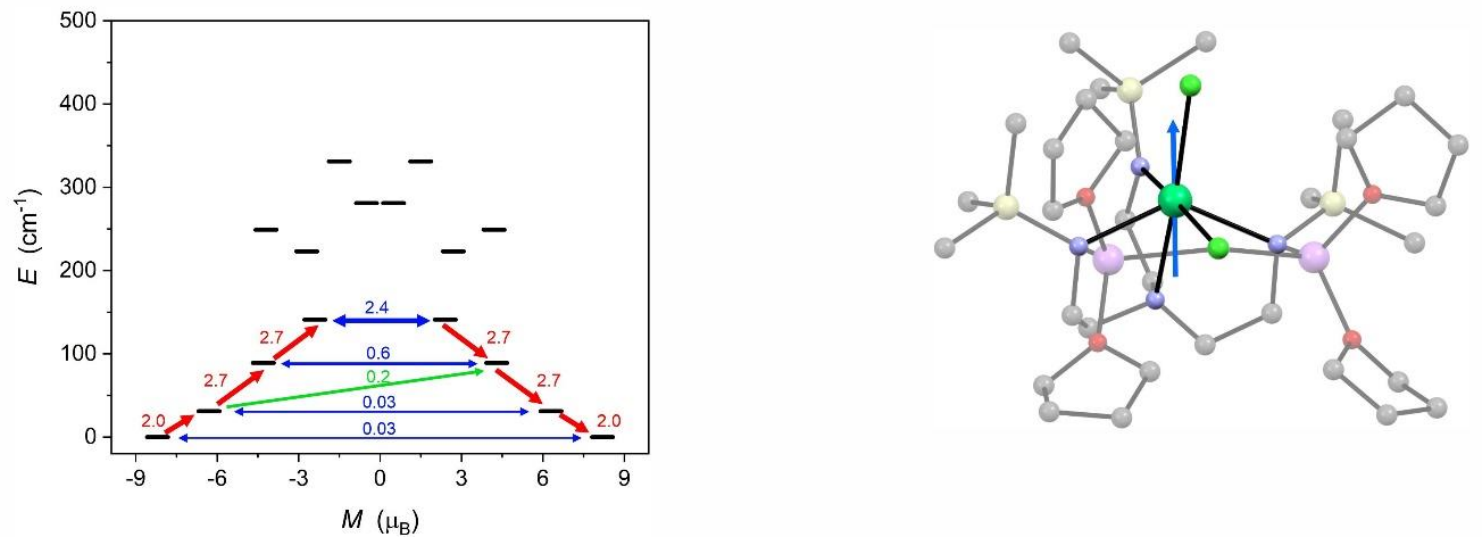

Figure 4. Left: energy spectrum of the calculated Kramers doublets (KDs) arising from the ${ }^{4} \mathrm{l}_{15 / 2}$ multiplet of Er ${ }^{\text {III }}$ of compound $\mathbf{1}$ (a), $\mathbf{3}$ (b) and $\mathbf{4}$ (c) with arrows corresponding to the most important magnetization relaxation pathways: Orbach (red), QTM and TA-QTM (blue) and Raman (green). Right: Structural fragments used for the CASSCF calculations with the blue arrow indicating the direction of the easy magnetization axis of the ground state KD for $\mathbf{1}(\mathrm{a}), \mathbf{3}$ (b) and $\mathbf{4}$ (c).

Magnetization dynamics for $\mathbf{1}$ and $\mathbf{3}$ is more difficult to explain. The first excited state in both cases is at ca. $100 \mathrm{~cm}^{-1}$, significantly higher than the experimental $U_{\text {eff }}$ of $44(2)$ and $33(2)$ $\mathrm{cm}^{-1}$, respectively. This suggests that the experimental $U_{\text {eff }}$ values for $\mathbf{1}$ and $\mathbf{3}$ are grossly underestimated and the Raman relaxation is the major relaxation pathway for these pseudotetrahedral SMMs. This is consistent with the experimental observations - the experimental data points in Figures $3 \mathrm{~b}$ and 3d show almost identical trend as that calculated solely for the Raman relaxation contribution in the entire investigated temperature range. While the Raman relaxation is typically encountered in molecular crystals, ${ }^{56}$ its manifestation in the pseudo-tetrahedral $\mathbf{1}$ and $\mathbf{3}$ uniquely 'pure' and might be related to the presence of the axially coordinated THF.

Attempts to calculate the energy diagram and magnetic properties of $\mathbf{2}$ were unsuccessful due to the additional spin on 
the TEMPO ligand. However, in order to better understand the crystal field in 2, we have replaced the $\mathrm{N}$ atom in TEMPO with the $\mathrm{C}$ atom so that the TEMPO has lost its radical character and the calculations were possible for such a modified model of $\mathbf{2}$ (Table S18 and S19 in the ESI). In this way the hypothetical energy diagram could be calculated. Interestingly, the first excited KD for such a modified model of compound $\mathbf{2}$ is placed only $44 \mathrm{~cm}^{-1}$ above the ground state (Table S18 in the ESI), which is much lower than that found for $\mathbf{1}$ and $\mathbf{3}$ despite very similar geometries of 1-3. While this lower energy gap would be consistent with the 'modified' $\mathbf{2}$ being worse SMM than the parent $\mathbf{1}$, it still does not explain the complete absence of the slow magnetic relaxation in the real system, since the obtained ground KD is still strongly axial (as one would expect because of the small difference of the first coordination sphere geometry compared 1). Again, this must be caused by the direct spin-spin relaxation involving the TEMPO radical which completely takes control of the magnetization dynamics in $\mathbf{2}$.

\section{Conclusions}

To summarize, we have synthesized and thoroughly characterized four new Er"ll compounds [ $\left.\mathrm{Er}^{\prime \prime \prime}(\mathrm{TTBP})_{3}(\mathrm{THF})\right](\mathbf{1})$, $\left[\mathrm{Er}^{\prime \prime \prime}(\mathrm{TTBP})_{3}(\mathrm{TEMPO})\right] \quad$ (2), $\quad\left[\mathrm{Er}^{\prime \prime \prime}(\mathrm{BHT})_{3}(\mathrm{THF})\right] \quad$ (3) and [Li(THF) $\left.]_{2}\right]_{2}\left[\mathrm{Er}^{\prime \prime \prime}\left(\mathrm{N}_{3} \mathrm{~N}\right) \mathrm{Cl}_{2}\right](4)$ of which 1 and $\mathbf{3}$ are rare pseudotetrahedral Er'II SMMs ${ }^{23,45,47}$ with exquisite slow magnetization dynamics featuring wide waist-restricted magnetic hysteresis loops at low temperature. The main driving force for exploring this rare Er ${ }^{\text {III }}$ geometry was the potential for substitution of the apical neutral THF ligands in $\mathbf{1}$ and $\mathbf{3}$ with carefully selected functional ligands such as TEMPO radical. As it appears such a substitution indeed occurs, but the resulting compound $\mathbf{2}$ does not show typical slow magnetization dynamics of its parent 1. Instead, it behaves as a simple paramagnet with weak-tomoderate antiferromagnetic interactions between $\mathrm{Er}^{\text {III }}$ and the coordinated paramagnetic TEMPO that appears to be the most possible reason for the quenching of the SMM behavior.

The thorough magneto-structural analysis of the reported pseudo-tetrahedral Er'II SMMs supported by ab initio calculations indicate that the slow magnetization dynamics in $\mathbf{1}$ and $\mathbf{3}$ under small external magnetic field is solely controlled by a Raman relaxation mechanism - an observation that is still often overlooked in the analysis of lanthanide-based SMMs, 56 but apparently of great importance in the reported pseudotetrahedral Er'II SMMs. Interestingly, this Raman-relaxationcontrolled behavior is completely absent in the pseudooctahedral 4, which shows Orbach relaxation behavior typical for most SMMs. This might be due to the more rigid ligand scaffold in 4, which limits the local vibrations around the Er"ll ion.

\section{Conflicts of interest}

There are no conflicts to declare.

\section{Acknowledgments}

This work was financed by the National Science Center within the Sonata Bis project (2016/22/E/ST5/00055). GH acknowledges the financial support of the Polish Ministry of Science and Higher Education within the Diamond Grant (0191/DIA/2017/46).

\section{References}

1. S. G. McAdams, A.-M. Ariciu, A. K. Kostopoulos, J. P. S. Walsh and F. Tuna, Coordination Chemistry Reviews, 2017, 346, 216-239.

2. E. Coronado, Nature Reviews Materials, 2020, 5, 87-104.

3. M. Feng and M.-L. Tong, Chemistry - A European Journal, 2018, 24, 7574-7594.

4. M. R. Wasielewski, M. D. E. Forbes, N. L. Frank, K. Kowalski, G. D. Scholes, J. Yuen-Zhou, M. A. Baldo, D. E. Freedman, R. H. Goldsmith, T. Goodson, M. L. Kirk, J. K. McCusker, J. P. Ogilvie, D. A. Shultz, S. Stoll and K. B. Whaley, Nature Reviews Chemistry, 2020, 4, 490-504.

5. S. L. Bayliss, D. W. Laorenza, P. J. Mintun, B. D. Kovos, D. E. Freedman and D. D. Awschalom, Science, 2020, 370, 1309-1312.

6. W. Wernsdorfer and R. Sessoli, Science, 1999, 284, 133135.

7. S. Hill, R. S. Edwards, N. Aliaga-Alcalde and G. Christou, Science, 2003, 302, 1015-1018.

8. K. Bader, D. Dengler, S. Lenz, B. Endeward, S.-D. Jiang, P. Neugebauer and J. van Slageren, Nature Communications, 2014, 5, 5304.

9. G. Handzlik, M. Magott, M. Arczyński, A. M. Sheveleva, F. Tuna, M. Sarewicz, A. Osyczka, M. Rams, V. Vieru, L. F. Chibotaru and D. Pinkowicz, The Journal of Physical Chemistry Letters, 2020, 11, 1508-1515.

10. S. Giménez-Santamarina, S. Cardona-Serra, J. M. Clemente-Juan, A. Gaita-Ariño and E. Coronado, Chemical Science, 2020, 11, 10718-10728.

11. C. A. P. Goodwin, F. Ortu, D. Reta, N. F. Chilton and D. P. Mills, Nature, 2017, 548, 439-442.

12. D. Pinkowicz, F. J. Birk, M. Magott, K. Schulte and K. R. Dunbar, Chemistry - A European Journal, 2017, 23, 35483552.

13. J.-L. Liu, Y.-C. Chen and M.-L. Tong, Chemical Society Reviews, 2018, 47, 2431-2453.

14. N. Ishikawa, M. Sugita, T. Ishikawa, S.-y. Koshihara and Y. Kaizu, Journal of the American Chemical Society, 2003, 125, 8694-8695.

15. F.-S. Guo, B. M. Day, Y.-C. Chen, M.-L. Tong, A. Mansikkamäki and R. A. Layfield, Science, 2018, DOI: 10.1126/science.aav0652, eaav0652.

16. S. Demir, M. I. Gonzalez, L. E. Darago, W. J. Evans and J. R. Long, Nature Communications, 2017, 8, 2144.

17. Y.-S. Meng, L. Xu, J. Xiong, Q. Yuan, T. Liu, B.-W. Wang and S. Gao, Angewandte Chemie International Edition, 2018, 57, 4673-4676.

18. O. Cador, B. Le Guennic and F. Pointillart, Inorganic Chemistry Frontiers, 2019, 6, 3398-3417.

19. M. Hojorat, H. Al Sabea, L. Norel, K. Bernot, T. Roisnel, F. Gendron, B. L. Guennic, E. Trzop, E. Collet, J. R. Long and 
S. Rigaut, Journal of the American Chemical Society, 2020, 142, 931-936.

Y. Xin, J. Wang, M. Zychowicz, J. J. Zakrzewski, K. Nakabayashi, B. Sieklucka, S. Chorazy and S.-i. Ohkoshi, Journal of the American Chemical Society, 2019, 141 18211-18220.

21. D. Pinkowicz, M. Ren, L.-M. Zheng, S. Sato, M. Hasegawa, M. Morimoto, M. Irie, B. K. Breedlove, G. Cosquer, K. Katoh and M. Yamashita, Chemistry - A European Journal, 2014, 20, 12502-12513.

22. Z. Zhu, X.-L. Li, S. Liu and J. Tang, Inorganic Chemistry Frontiers, 2020, 7, 3315-3326.

23. C. M. Dickie, A. L. Laughlin, J. D. Wofford, N. S. Bhuvanesh and M. Nippe, Chemical Science, 2017, 8, 8039-8049.

24. A. Palii, J. M. Clemente-Juan, S. Aldoshin, D. Korchagin, A. Rybakov, S. Zilberg and B. Tsukerblat, The Journal of Physical Chemistry C, 2020, 124, 25602-25614.

25. A. Palii, S. Aldoshin and B. Tsukerblat, Coordination Chemistry Reviews, 2021, 426, 213555.

26. M. Arczyński, J. Stanek, B. Sieklucka, K. R. Dunbar and D. Pinkowicz, Journal of the American Chemical Society, 2019, 141, 19067-19077.

27. Y.-S. Ding, T. Han, Y.-Q. Zhai, D. Reta, N. F. Chilton, R. E. P. Winpenny and Y.-Z. Zheng, Chemistry - A European Journal, 2020, 26, 5893-5902.

28. A. B. Canaj, M. K. Singh, E. Regincós Marti, M. Damjanović, C. Wilson, O. Céspedes, W. Wernsdorfer, G. Rajaraman and M. Murrie, Chemical Communications, 2019, 55, 5950-5953.

29. A. B. Canaj, S. Dey, O. Céspedes, C. Wilson, G. Rajaraman and M. Murrie, Chemical Communications, 2020, 56, 1533-1536.

30. G. Lu, Y. Liu, W. Deng, G.-Z. Huang, Y.-C. Chen, J.-L. Liu, Z.P. Ni, M. Giansiracusa, N. F. Chilton and M.-L. Tong, Inorganic Chemistry Frontiers, 2020, 7, 2941-2948.

31. Y.-S. Ding, N. F. Chilton, R. E. P. Winpenny and Y.-Z. Zheng Angewandte Chemie International Edition, 2016, 55, 16071-16074.

32. T. P. Latendresse, N. S. Bhuvanesh and M. Nippe, Journal of the American Chemical Society, 2017, 139, 1487714880.

33. C. A. Gould, E. Mu, V. Vieru, L. E. Darago, K. Chakarawet, M. I. Gonzalez, S. Demir and J. R. Long, Journal of the American Chemical Society, 2020, 142, 21197-21209.

34. C. Wang, R. Sun, Y. Chen, B.-W. Wang, Z.-M. Wang and S. Gao, CCS Chemistry, 2020, 2, 362-368.

35. Y. Wang, J. Xiong, J. Su, Z. Hu, F. Ma, R. Sun, X. Tan, H.-L. Sun, B.-W. Wang, Z. Shi and S. Gao, Nanoscale, 2020, 12, 11130-11135.

36. C. Gao, Q. Yang, B.-W. Wang, Z.-M. Wang and S. Gao, CrystEngComm, 2016, 18, 4165-4171.

37. Y.-S. Meng, C.-H. Wang, Y.-Q. Zhang, X.-B. Leng, B.-W. Wang, Y.-F. Chen and S. Gao, Inorganic Chemistry Frontiers, 2016, 3, 828-835.

38. L. Münzfeld, C. Schoo, S. Bestgen, E. Moreno-Pineda, R. Köppe, M. Ruben and P. W. Roesky, Nature Communications, 2019, 10, 3135.

39. S.-M. Chen, J. Xiong, Y.-Q. Zhang, Q. Yuan, B.-W. Wang and S. Gao, Chemical Science, 2018, 9, 7540-7545.

40.
41.

Ungur, J. J. Le Roy, I. Korobkov, M. Murugesu and L. F. Chibotaru, Angewandte Chemie International Edition, 2014, 53, 4413-4417.

42. K. R. Meihaus and J. R. Long, Journal of the American Chemical Society, 2013, 135, 17952-17957.

43. J. J. Le Roy, L. Ungur, I. Korobkov, L. F. Chibotaru and M. Murugesu, Journal of the American Chemical Society, 2014, 136, 8003-8010.

44. P. Zhang, L. Zhang, C. Wang, S. Xue, S.-Y. Lin and J. Tang, Journal of the American Chemical Society, 2014, 136, 4484-4487.

45. A. J. Brown, D. Pinkowicz, M. R. Saber and K. R. Dunbar, Angewandte Chemie International Edition, 2015, 54, 5864-5868.

46. H. Zhang, R. Nakanishi, K. Katoh, B. K. Breedlove, Y. Kitagawa and M. Yamashita, Dalton Transactions, 2018, 47, 302-305.

47. P. Zhang, J. Jung, L. Zhang, J. Tang and B. Le Guennic, Inorganic Chemistry, 2016, 55, 1905-1911.

48. G. Handzlik, M. Magott, M. Arczyński, A. M. Sheveleva, F. Tuna, S. Baran and D. Pinkowicz, Dalton Transactions, 2020, 49, 11942-11949.

49. Z. Jin, J. Bai, T. Wei, F. Li, C. Song, X. Luo and L. Xu, New Journal of Chemistry, 2017, 41, 13490-13494.

50. M. A. AlDamen, J. M. Clemente-Juan, E. Coronado, C. Martí-Gastaldo and A. Gaita-Ariño, Journal of the American Chemical Society, 2008, 130, 8874-8875.

51. A. Gorczyński, M. Kubicki, D. Pinkowicz, R. Pełka, V. Patroniak and R. Podgajny, Dalton Transactions, 2015, 44, 16833-16839.

52. K. Kumar, O. Stefańczyk, S. Chorazy, K. Nakabayashi, B. Sieklucka and S.-i. Ohkoshi, Inorganic Chemistry, 2019, 58, 5677-5687.

53. R. Jankowski, J. J. Zakrzewski, O. Surma, S.-i. Ohkoshi, S. Chorazy and B. Sieklucka, Inorganic Chemistry Frontiers, 2019, 6, 2423-2434.

54. I. A. Kühne, L. Ungur, K. Esien, A. B. Carter, J. D. Gordon, C. Pauly, H. Müller-Bunz, S. Felton, D. Zerulla and G. G. Morgan, Dalton Transactions, 2019, 48, 15679-15686.

55. R. Herchel, P. Zoufalý and I. Nemec, RSC Advances, 2019, 9, 569-575.

56. L. Gu and R. Wu, Physical Review B, 2021, 103, 014401

57. G. Deacon, T. Feng, S. Nickel, M. Ogden and A. White, Australian Journal of Chemistry, 1992, 45, 671-683.

58. C. C. Cummins, R. R. Schrock and W. M. Davis, Organometallics, 1992, 11, 1452-1454.

59. C. C. Cummins, J. Lee, R. R. Schrock and W. D. Davis, Angewandte Chemie International Edition in English, 1992, 31, 1501-1503.

60. X. Lin, W. Wu and Y. Mo, Coordination Chemistry Reviews, 2020, 419, 213401.

61. E. D. Brady, D. L. Clark, J. C. Gordon, P. J. Hay, D. W. Keogh, R. Poli, B. L. Scott and J. G. Watkin, Inorganic Chemistry, 2003, 42, 6682-6690.

62. H. M. Nicholas, M. Vonci, C. A. P. Goodwin, S. W. Loo, S. R Murphy, D. Cassim, R. E. P. Winpenny, E. J. L. Mclnnes, N. F. Chilton and D. P. Mills, Chemical Science, 2019, 10, 10493-10502.

63. J. Cirera, P. Alemany and S. Alvarez, Chemistry - A European Journal, 2004, 10, 190-207.

64. R. Murakami, T. Nakamura and T. Ishida, Dalton Transactions, 2014, 43, 5893-5898.

65. L. B. L. Escobar, G. P. Guedes, S. Soriano, N. L. Speziali, A. K. Jordão, A. C. Cunha, V. F. Ferreira, C. Maxim, M. A. 
Novak, M. Andruh and M. G. F. Vaz, Inorganic Chemistry, 2014, 53, 7508-7517.

66. G. Huang, C. Daiguebonne, G. Calvez, Y. Suffren, O.

Guillou, T. Guizouarn, B. Le Guennic, O. Cador and K. Bernot, Inorganic Chemistry, 2018, 57, 11044-11057.

67. D. Bordeaux, A. Capiomont, J. Lajzerowicz-Bonneteau, M. Jouve and M. Thomas, Acta Crystallographica Section B, 1974, 30, 2156-2160.

68. M. Arczyński and D. Pinkowicz, Inorganic Chemistry, 2020, 59, 13489-13501.

69. S. Alvarez, D. Avnir, M. Llunell and M. Pinsky, New Journal of Chemistry, 2002, 26, 996-1009.

70. K. Olivier, Molecular magnetism, VCH Publishers, New York, 1993.

71. D. Gatteschi, R. Sessoli and J. Villain, Molecular Nanomagnets, Oxford University Press, New York, 2006.

72. S. T. Liddle and J. van Slageren, Chemical Society Reviews, 2015, 44, 6655-6669.

73. C. Richard L., Magnetochemistry, Springer-Verlag, Berlin, 1986.

74. F. Aquilante, J. Autschbach, R. K. Carlson, L. F. Chibotaru, M. G. Delcey, L. De Vico, I. Fdez. Galván, N. Ferré, L. M. Frutos, L. Gagliardi, M. Garavelli, A. Giussani, C. E. Hoyer, G. Li Manni, H. Lischka, D. Ma, P. A.. Malmqvist, T. Müller, A. Nenov, M. Olivucci, T. B. Pedersen, D. Peng, F. Plasser, B. Pritchard, M. Reiher, I. Rivalta, I. Schapiro, J. SegarraMartí, M. Stenrup, D. G. Truhlar, L. Ungur, A. Valentini, S. Vancoillie, V. Veryazov, V. P. Vysotskiy, O. Weingart, F. Zapata and R. Lindh, Journal of Computational Chemistry, 2016, 37, 506-541.

75. L. Ungur and L. F. Chibotaru, Inorganic Chemistry, 2016, 55, 10043-10056.

76. F. Lu, M.-M. Ding, J.-X. Li, B.-L. Wang and Y.-Q. Zhang, Dalton Transactions, 2020, 49, 14576-14583. 